\title{
Prediction of Cancer Incidence and Mortality in Korea, 2019
}

\section{Kyu-Won Jung, MS ${ }^{1,2}$ \\ Young-Joo Won, $\mathrm{PhD}^{1,2,3}$ \\ Hyun-Joo Kong, MS 1,2 \\ Eun Sook Lee, MD, PhD ${ }^{1,4}$}

${ }^{1}$ The Korea Central Cancer Registry, National Cancer Center, Goyang,

${ }^{2}$ National Cancer Control Institute, National Cancer Center, Goyang, ${ }^{3}$ Department of Cancer Control and Population Health, National Cancer Center Graduate School of Cancer Science and Policy, National Cancer Center, Goyang, ${ }^{4}$ Department of Cancer Control and Population Health, National Cancer Center Graduate School of Cancer Science and Policy,

National Cancer Center, Goyang, Korea
Correspondence: Young-Joo Won, $\mathrm{PhD}$

The Korea Central Cancer Registry,

National Cancer Center, 323 Ilsan-ro,

Ilsandong-gu, Goyang 10408, Korea

Tel: 82-31-920-2015

Fax: 82-31-920-2179

E-mail: astra67@ncc.re.kr

Received March 12, 2019

Accepted March 13, 2019

Published Online March 18, 2019

\section{Purpose}

This study aimed to report on cancer incidence and mortality for the year 2019 to estimate Korea's current cancer burden.

\section{Materials and Methods}

Cancer incidence data from 1999 to 2016 were obtained from the Korea National Cancer Incidence Database, and cancer mortality data from 1993 to 2017 were acquired from Statistics Korea. Cancer incidence and mortality were projected by fitting a linear regression model to observed age-specific cancer rates against observed years, then multiplying the projected age-specific rates by the age-specific population. The Joinpoint regression model was used to determine at which year the linear trend changed significantly; we used only the data of the latest trend.

\section{Results}

A total of 221,347 new cancer cases and 82,344 cancer deaths are expected to occur in Korea in 2019. The most common cancer sites thus far have been the lung, followed by the stomach, colon and rectum, breast, and liver. These five cancers represent half of the overall burden of cancer in Korea. For cancer associated mortality, the most common sites were lung, followed by the liver, colon and rectum, stomach, and pancreas.

\section{Conclusion}

The incidence rate of all cancer in Korea is estimated to decrease gradually. These up-todate estimates of the cancer burden in Korea could be an important resource for planning and evaluating cancer-control programs.

\section{Introduction}

As the leading cause of death in Korea [1], cancer has been the country's major public health concern since 1983. Over 220,000 patients were newly diagnosed with cancer in Korea, and one in four deaths is due to cancer [2]. Although the cancer registration system in Korea is highly efficient and can provide nationwide cancer statistics within a relatively short period, a lag time of at least 2 years is required to collect and

\section{Key words}

Incidence, Mortality, Neoplasms, Forecasting, Korea, 2019 


\section{Materials and Methods}

The Korean Ministry of Health and Welfare initiated a nationwide, hospital-based cancer registry, the Korea Central Cancer Registry (KCCR), in 1980. The history, objectives, and activities of the KCCR have been documented in detail elsewhere [3]. Incidence data from 1999 to 2016 were obtained from the Korea National Cancer Incidence Database (KNCI DB). Cancer cases were classified according to the International Classification of Diseases for Oncology, third edition [4], and converted according to the International Classification of Diseases, 10th edition (ICD-10) [5]. Mortality data from 1993 to 2017 were acquired from Statistics Korea [1]. The cause of death was coded and classified according to ICD-10 [5].

The cancer sites included in this study were (1) all cancers sites combined and (2) the 24 common cancer sites as follows: lips, oral cavity, and pharynx (C00-C14), esophagus (C15), stomach (C16), colon and rectum (C18-C20), liver and intrahepatic bile duct (liver) (C22), gallbladder and other parts of the biliary tract (gallbladder) (C23-C24), pancreas (C25), larynx (C32), trachea, bronchus and lung (lung) (C33-C34), breast (C50), cervix uteri (C53), corpus uteri (C54), ovary (C56), prostate (C61), testis (C62), kidney (C64), bladder (C67), brain and central nervous system (C70-C72), thyroid (C73), Hodgkin lymphoma (C81), non-Hodgkin lymphoma (C82C86, C96), multiple myeloma (C90), leukemia (C91-C95), and 'other and ill defined' sites.

Population data from 1993 to 2019 were obtained from the resident registration population data, reported by Statistics Korea. Data on the mid-year population, as of July 1 of the respective year, were analyzed. However, we used population data as of December 31, 2018 for the year 2019, because mid-2019 resident registration population data were not yet available at the time of analysis.

Linear regression models [6] were used to assess time trends and projections. We first performed a Joinpoint reg-

Table 1. Estimated new cancer cases and deaths by sex during 2019 in Korea

\begin{tabular}{|c|c|c|c|c|c|c|}
\hline \multirow{2}{*}{ Site } & \multicolumn{3}{|c|}{ Estimated new cases } & \multicolumn{3}{|c|}{ Estimated deaths } \\
\hline & Both sexes & Male & Female & Both sexes & Male & Female \\
\hline All sites & 221,347 & 120,352 & 100,995 & 82,344 & 50,352 & 31,992 \\
\hline Lip, oral cavity, and pharynx & 3,789 & 2,736 & 1,053 & 1,221 & 897 & 324 \\
\hline Esophagus & 2,548 & 2,318 & 230 & 1,321 & 1,173 & 148 \\
\hline Stomach & 27,175 & 18,039 & 9,136 & 6,729 & 4,349 & 2,380 \\
\hline Colon and rectum & 25,330 & 14,478 & 10,852 & 8,653 & 4,813 & 3,840 \\
\hline Liver $^{\text {a) }}$ & 15,016 & 11,281 & 3,735 & 10,720 & 7,824 & 2,896 \\
\hline Gallbladderb) & 7,677 & 4,081 & 3,596 & 4,750 & 2,353 & 2,397 \\
\hline Pancreas & 7,927 & 4,135 & 3,792 & 6,609 & 3,380 & 3,229 \\
\hline Larynx & 1,095 & 1,035 & 60 & 292 & 292 & 0 \\
\hline Lung $^{c)}$ & 28,107 & 19,700 & 8,407 & 19,488 & 14,254 & 5,234 \\
\hline Breast & 24,100 & 90 & 24,010 & 2,727 & 21 & 2,706 \\
\hline Cervix uteri & 2,856 & - & 2,856 & 834 & - & 834 \\
\hline Corpus uteri & 3,061 & - & 3,061 & 372 & - & 372 \\
\hline Ovary & 2,832 & - & 2,832 & 1,271 & - & 1,271 \\
\hline Prostate & 13,326 & 13,326 & - & 2,281 & 2,281 & - \\
\hline Testis & 313 & 313 & - & 18 & 18 & - \\
\hline Kidney & 5,609 & 3,794 & 1,815 & 1,189 & 816 & 373 \\
\hline Bladder & 4,721 & 3,745 & 976 & 1,610 & 1,216 & 394 \\
\hline Brain and $\mathrm{CNS}$ & 2,087 & 1,123 & 964 & 1,332 & 694 & 638 \\
\hline Thyroid & 11,667 & 3,163 & 8,504 & 340 & 92 & 248 \\
\hline Hodgkin lymphoma & 340 & 217 & 123 & 61 & 40 & 21 \\
\hline Non-Hodgkin lymphoma & 5,264 & 3,046 & 2,218 & 2,051 & 1,182 & 869 \\
\hline Multiple myeloma & 1,944 & 1,049 & 895 & 1,140 & 615 & 525 \\
\hline Leukemia & 3,683 & 2,123 & 1,560 & 1,935 & 1,093 & 842 \\
\hline Other and ill defined & 20,880 & 10,560 & 10,320 & 5,400 & 2,949 & 2,451 \\
\hline
\end{tabular}

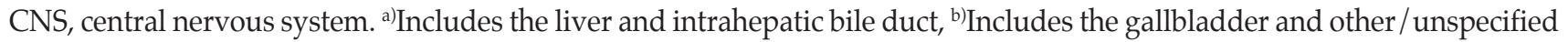
parts of the biliary tract, ${ }^{\mathrm{c}}$ Includes the trachea, bronchus, and lung. 


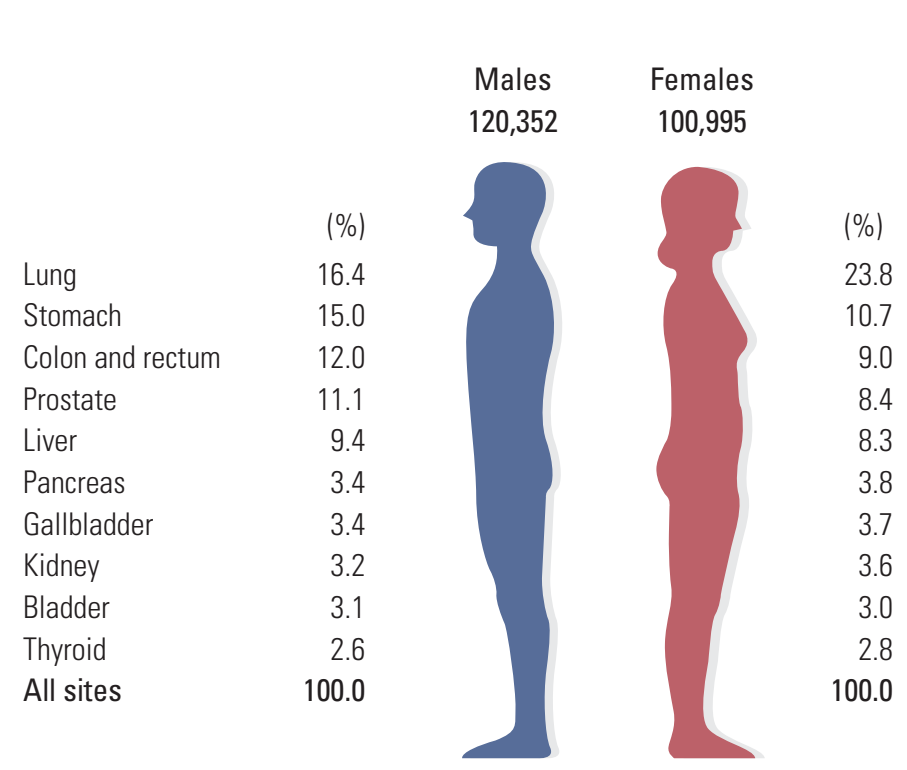

23.8

10.7

9.0

8.4

8.3

3.8

3.7

3.6

3.0

2.8

00.0

$$
\begin{array}{r}
\text { Breast } \\
\text { Colon and rectum } \\
\text { Stomach } \\
\text { Thyroid } \\
\text { Lung } \\
\text { Pancreas } \\
\text { Liver } \\
\text { Gallbladder } \\
\text { Cervix corpus } \\
\text { Cervix uteri } \\
\text { All sites }
\end{array}
$$

\begin{tabular}{|c|c|c|c|c|c|}
\hline & & $\begin{array}{l}\text { Males } \\
50,352\end{array}$ & $\begin{array}{c}\text { Females } \\
31,992\end{array}$ & & \\
\hline & $(\%)$ & & & $(\%)$ & \\
\hline Lung & 28.3 & & & 16.4 & Lung \\
\hline Liver & 15.5 & & & 12.0 & Colon and rectum \\
\hline Colon and rectum & 9.6 & & & 10.1 & Pancreas \\
\hline Stomach & 8.6 & & & 9.1 & Liver \\
\hline Pancreas & 6.7 & & & 8.5 & Breast \\
\hline Gallbladder & 4.7 & & & 7.5 & Gallbladder \\
\hline Prostate & 4.5 & & & 7.4 & Stomach \\
\hline Bladder & 2.4 & & & 4.0 & Ovary \\
\hline Non-Hodgkin lymphoma & 2.3 & & & 2.7 & Non-Hodgkin lymphoma \\
\hline Esophagus & 2.3 & & & 2.6 & Leukemia \\
\hline All sites & 100.0 & & & 100.0 & All sites \\
\hline
\end{tabular}

\section{B}

Fig. 1. The 10 leading types of estimated new cancer cases and deaths by sex in 2019. (A) Estimated new cases. (B) Estimated deaths.

ression analysis on the data available to detect the year when significant changes occurred in cancer trends according to sex and cancer site. A Joinpoint regression describes changes in data trends by connecting several different line segments on a log scale at "joinpoints." This analysis was performed using the Joinpoint software (ver. 4.3.1, http:// surveillance. cancer.gov/joinpoint) from the Surveillance Research Program of the US National Cancer Institute [7]. For the analysis, we arranged to have at least four data points between consecutive joinpoints. Secondly, to predict age-specific cancer rates, a linear regression model was fitted to age-specific rates by 5 -year age groups against observed years based on observed cancer incidence data of the latest trend. Finally, we multiply the projected age-specific rates by the age-specific population to get the projected cancer cases and deaths of the year 2019. For thyroid cancer, we used a square root 
Table 2. Estimated crude and age-standardized cancer incidences by sex during 2019 in Korea

\begin{tabular}{|c|c|c|c|c|c|c|}
\hline \multirow[t]{2}{*}{ Site } & \multicolumn{3}{|c|}{$\begin{array}{c}\text { Crude incidence rate } \\
\text { per } 100,000\end{array}$} & \multicolumn{3}{|c|}{$\begin{array}{l}\text { Age-standardized incidence rate } \\
\left.\text { per } 100,000^{\mathrm{a}}\right)\end{array}$} \\
\hline & Both sexes & Male & Female & Both sexes & Male & Female \\
\hline All sites & 427.2 & 463.5 & 390.8 & 233.5 & 264.1 & 215.4 \\
\hline Lip, oral cavity, and pharynx & 7.3 & 10.5 & 4.1 & 4.2 & 6.2 & 2.4 \\
\hline Esophagus & 4.9 & 8.9 & 0.9 & 2.4 & 4.8 & 0.4 \\
\hline Stomach & 52.5 & 69.5 & 35.4 & 27.1 & 38.8 & 16.9 \\
\hline Colon and rectum & 48.9 & 55.8 & 42.0 & 24.2 & 30.9 & 18.4 \\
\hline Liver $^{\mathrm{b})}$ & 29.0 & 43.5 & 14.5 & 14.8 & 24.3 & 6.4 \\
\hline Gallbladderc) & 14.8 & 15.7 & 13.9 & 6.7 & 8.4 & 5.4 \\
\hline Pancreas & 15.3 & 15.9 & 14.7 & 7.3 & 8.7 & 6.1 \\
\hline Larynx & 2.1 & 4.0 & 0.2 & 1.1 & 2.1 & 0.1 \\
\hline Lung $^{\text {d) }}$ & 54.3 & 75.9 & 32.5 & 25.9 & 40.3 & 14.8 \\
\hline Breast & 46.5 & 0.4 & 92.9 & 29.3 & 0.2 & 58.4 \\
\hline Cervix uteri & 5.5 & 0.0 & 11.1 & 3.5 & - & 6.9 \\
\hline Corpus uteri & 5.9 & 0.0 & 11.8 & 3.6 & - & 7.2 \\
\hline Ovary & 5.5 & 0.0 & 11.0 & 3.4 & - & 6.8 \\
\hline Prostate & 25.7 & 51.3 & 0.0 & 12.4 & 27.4 & - \\
\hline Testis & 0.6 & 1.2 & 0.0 & 0.6 & 1.2 & - \\
\hline Kidney & 10.8 & 14.6 & 7.0 & 6.2 & 8.8 & 3.8 \\
\hline Bladder & 9.1 & 14.4 & 3.8 & 4.3 & 7.7 & 1.6 \\
\hline Brain and $\mathrm{CNS}$ & 4.0 & 4.3 & 3.7 & 3.0 & 3.4 & 2.6 \\
\hline Thyroid & 22.5 & 12.2 & 32.9 & 17.2 & 9.0 & 25.8 \\
\hline Hodgkin lymphoma & 0.7 & 0.8 & 0.5 & 0.6 & 0.7 & 0.4 \\
\hline Non-Hodgkin lymphoma & 10.2 & 11.7 & 8.6 & 6.3 & 7.8 & 5.0 \\
\hline Multiple myeloma & 3.8 & 4.0 & 3.5 & 1.9 & 2.2 & 1.6 \\
\hline Leukemia & 7.1 & 8.2 & 6.0 & 5.5 & 6.5 & 4.6 \\
\hline Other and ill defined & 40.3 & 40.7 & 39.9 & 22.1 & 24.8 & 19.7 \\
\hline
\end{tabular}

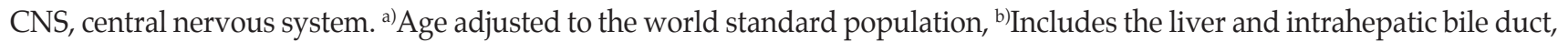
${ }^{c}$ Includes the gallbladder and other/ unspecified parts of the biliary tract, ${ }^{\mathrm{d}}$ Includes the trachea, bronchus, and lung.

transformation when fitting a linear regression model and converted the predicted values back to the original scale.

We summarized the results by using crude rates (CRs) and age-standardized rates (ASRs) of cancer incidence and mortality. ASRs were standardized using the world standard population [8] and expressed per 100,000 persons.

\section{Results}

\section{Incidence}

A total of 221,347 new cancer cases are anticipated in 2019 (Table 1, Fig. 1), and more males ( $n=120,352)$ than females $(n=100,995)$ are expected to be affected.

The projected CRs per 100,000 of all sites combined in 2019 are expected to be 463.5 and 390.8 in men and women, respectively (Table 2). The projected ASRs per 100,000 of all sites combined is 264.1 and 215.4 for men and women, respectively. In men, the five leading primary sites of cancer are expected to be the lung (CR, 75.9; ASR, 40.3), stomach (CR, 69.5; ASR, 38.8), colon and rectum (CR, 55.8; ASR, 30.9), prostate (CR, 51.3; ASR, 27.4), and liver (CR, 43.5; ASR, 24.3), accounting for $63.8 \%$ of all new cancers in 2019 .

In women, the five leading primary sites are expected to be the breast (CR, 92.9; ASR, 58.4), colon and rectum (CR, 42.0; ASR, 18.4), stomach (CR, 35.4; ASR, 16.9), thyroid (CR, 32.9; ASR, 25.8), and lung (CR, 32.5; ASR, 14.8), accounting for $60.3 \%$ of all new cancers (Fig. 1).

The five most common cancer sites expected in 2019 by sex and age groups are shown in Table 3. Leukemia and thyroid cancer are expected to be the most common forms of cancer in both sexes for the 0-14 and 15-34 age groups. Stomach cancer is predicted to be the most prevalent cancer in men aged 
Table 3. Estimated cancer incidence by age group and sex during 2019 in Korea

\begin{tabular}{|c|c|c|c|c|}
\hline \multirow{2}{*}{ Rank } & \multicolumn{4}{|c|}{ Age group (yr) } \\
\hline & $0-14$ & $15-34$ & $35-64$ & $\geq 65$ \\
\hline \multicolumn{5}{|l|}{ Male } \\
\hline 1 & Leukemia (5.0) & Thyroid (10.7) & Stomach $(68.3)$ & Lung $^{\text {a) }}(429.8)$ \\
\hline 2 & Non-Hodgkin lymphoma (3.1) & Leukemia (3.7) & Colon and rectum (47.6) & Prostate (306.0) \\
\hline 3 & Brain and CNS (2.3) & Non-Hodgkin lymphoma (3.2) & Liver $^{\mathrm{a})}(47.0)$ & Stomach (287.8) \\
\hline 4 & Kidney $(0.4)$ & Testis $(2.7)$ & Lung (43.8) & Colon and rectum (254.4) \\
\hline 5 & Liver $^{\mathrm{b})}(0.4)$ & Colon and rectum (2.3) & Prostate $(25.9)$ & Livera) $^{a}(163.1)$ \\
\hline \multicolumn{5}{|c|}{ Female } \\
\hline 1 & Leukemia (4.3) & Thyroid (32.9) & Breast (157.2) & Colon and rectum (162.5) \\
\hline 2 & Brain and CNS (1.9) & Breast (11.9) & Thyroid (45.9) & Lung $^{\text {b) }}(119.5)$ \\
\hline 3 & Non-Hodgkin lymphoma (1.7) & Cervix uteri (5.7) & Stomach (31.3) & Stomach (118.8) \\
\hline 4 & Ovary $(0.7)$ & Ovary (3.3) & Colon and rectum (29.7) & Breast (95.1) \\
\hline 5 & Kidney (0.4) & Leukemia (2.4) & Lung $^{\text {b) }}(25.4)$ & Gallbladder ${ }^{c}(64.5)$ \\
\hline
\end{tabular}

CNS, central nervous system. ${ }^{a}$ Includes the trachea, bronchus, and lung, ${ }^{b}$ Includes the liver and intrahepatic bile duct, c)Includes the gallbladder and other/ unspecified parts of the biliary tract.
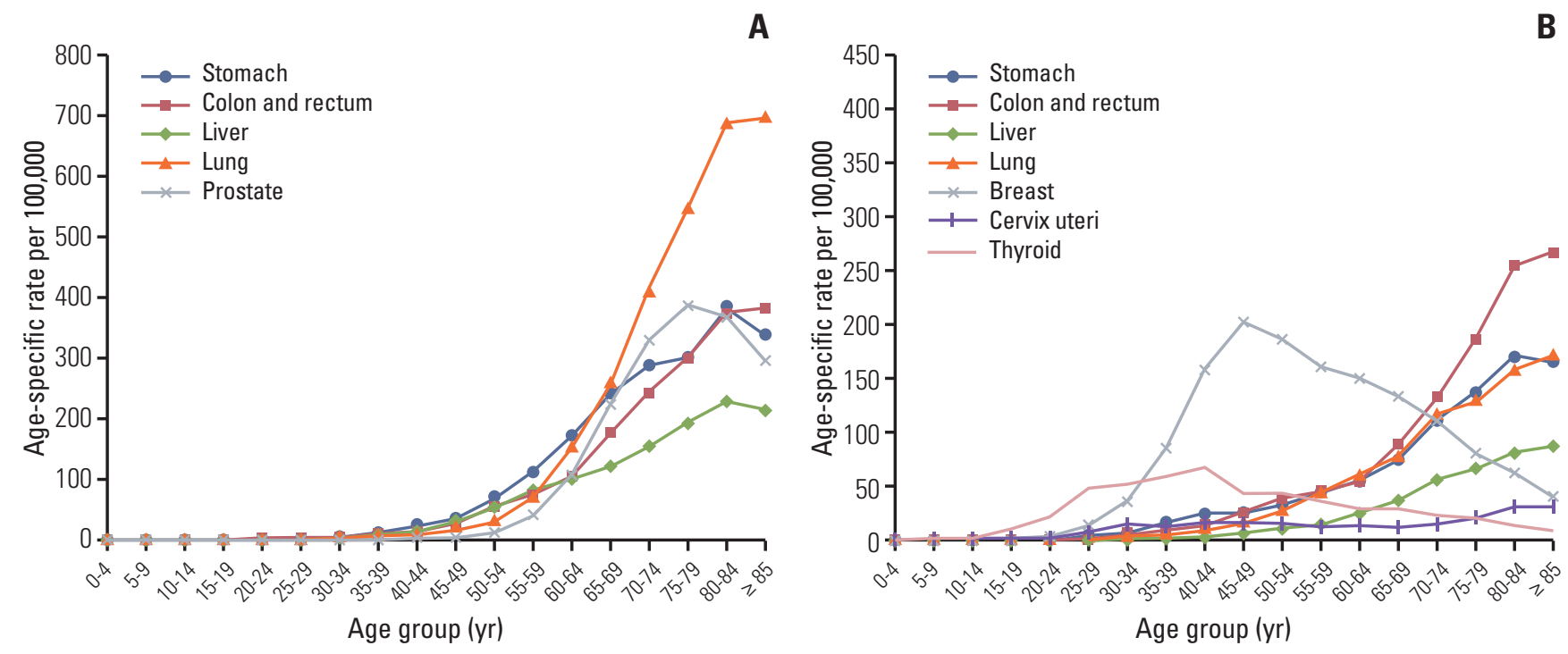

Fig. 2. Projected age-specific incidences of major cancers during 2019 in Korea. (A) Male. (B) Female.

35-64 years, while lung cancer is expected to be more frequent in men aged 65 years and above. Breast cancer is predicted to be the most common cancer in women aged 35-64 years, whereas colorectal cancer is expected to be the most prevalent in women aged 65 years and above. These projections indicate that the incidences of stomach, lung, liver, colorectal and prostate cancers will increase gradually with age for men (Fig. 2). In women, the age-specific incidence rates of stomach, colorectal, liver, lung, and cervical cancers denote a rising trend in these cancers with age; however, the incidence of breast and thyroid cancers in women is expected to level off after the age of 40 .

\section{Mortality}

It is estimated that 82,344 cancer deaths will occur in Korea during 2019 (Table 1, Fig. 1). The projected CRs per 100,000 of all sites combined in 2019 for men and women are pro- 
Table 4. Estimated crude and age-standardized cancer mortality rates by sex during 2019 in Korea

\begin{tabular}{|c|c|c|c|c|c|c|}
\hline \multirow[t]{2}{*}{ Site } & \multicolumn{3}{|c|}{$\begin{array}{l}\text { Crude mortality rate } \\
\text { per } 100,000\end{array}$} & \multicolumn{3}{|c|}{$\begin{array}{l}\text { Age-standardized mortality rate } \\
\text { per } 100,000^{\mathrm{a})}\end{array}$} \\
\hline & Both sexes & Male & Female & Both sexes & Male & Female \\
\hline All sites & 158.9 & 193.9 & 123.8 & 71.9 & 102.7 & 49.4 \\
\hline Lip, oral cavity, and pharynx & 2.4 & 3.5 & 1.3 & 1.1 & 1.9 & 0.5 \\
\hline Esophagus & 2.6 & 4.5 & 0.6 & 1.1 & 2.3 & 0.2 \\
\hline Stomach & 13.0 & 16.8 & 9.2 & 5.7 & 8.9 & 3.3 \\
\hline Colon and rectum & 16.7 & 18.5 & 14.9 & 7.3 & 9.8 & 5.2 \\
\hline Liver $^{\mathrm{b})}$ & 20.7 & 30.1 & 11.2 & 9.8 & 16.3 & 4.2 \\
\hline Gallbladderc) & 9.2 & 9.1 & 9.3 & 3.7 & 4.6 & 3.1 \\
\hline Pancreas & 12.8 & 13.0 & 12.5 & 5.8 & 7.0 & 4.7 \\
\hline Larynx & 0.6 & 1.1 & 0.0 & 0.2 & 0.6 & 0.0 \\
\hline Lung $^{\text {d) }}$ & 37.6 & 54.9 & 20.3 & 16.2 & 28.0 & 7.5 \\
\hline Breast & 5.3 & 0.1 & 10.5 & 3.0 & 0.0 & 5.7 \\
\hline Cervix uteri & 1.6 & - & 3.2 & 0.8 & - & 1.6 \\
\hline Corpus uteri & 0.7 & - & 1.4 & 0.4 & - & 0.7 \\
\hline Ovary & 2.5 & - & 4.9 & 1.3 & - & 2.4 \\
\hline Prostate & 4.4 & 8.8 & - & 1.7 & 4.5 & - \\
\hline Testis & 0.0 & 0.1 & - & 0.0 & 0.1 & - \\
\hline Kidney & 2.3 & 3.1 & 1.4 & 1.1 & 1.7 & 0.6 \\
\hline Bladder & 3.1 & 4.7 & 1.5 & 1.2 & 2.4 & 0.5 \\
\hline Brain and CNS & 2.6 & 2.7 & 2.5 & 1.6 & 1.8 & 1.4 \\
\hline Thyroid & 0.7 & 0.4 & 1.0 & 0.3 & 0.2 & 0.3 \\
\hline Hodgkin lymphoma & 0.1 & 0.2 & 0.1 & 0.1 & 0.1 & 0.0 \\
\hline Non-Hodgkin lymphoma & 4.0 & 4.6 & 3.4 & 1.8 & 2.5 & 1.3 \\
\hline Multiple myeloma & 2.2 & 2.4 & 2.0 & 1.0 & 1.3 & 0.8 \\
\hline Leukemia & 3.7 & 4.2 & 3.3 & 2.0 & 2.6 & 1.6 \\
\hline Other and ill defined & 10.4 & 11.4 & 9.5 & 4.9 & 6.3 & 3.8 \\
\hline
\end{tabular}

CNS, central nervous system. a)Age adjusted to the world standard population, b)Includes the liver and intrahepatic bile duct, c)Includes the gallbladder and other/ unspecified parts of the biliary tract, ${ }^{\mathrm{d}}$ Includes the trachea, bronchus, and lung.

A

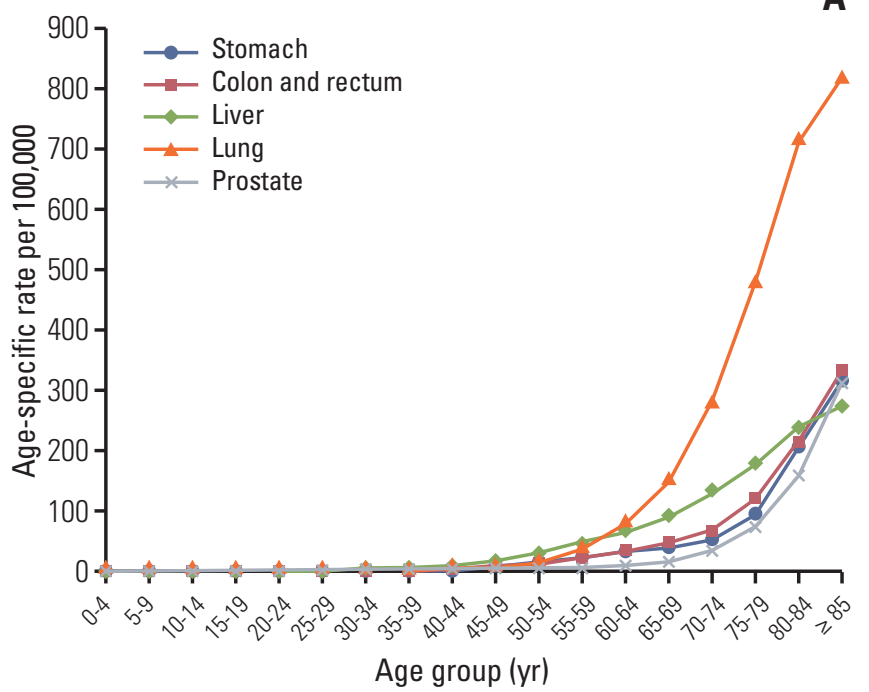

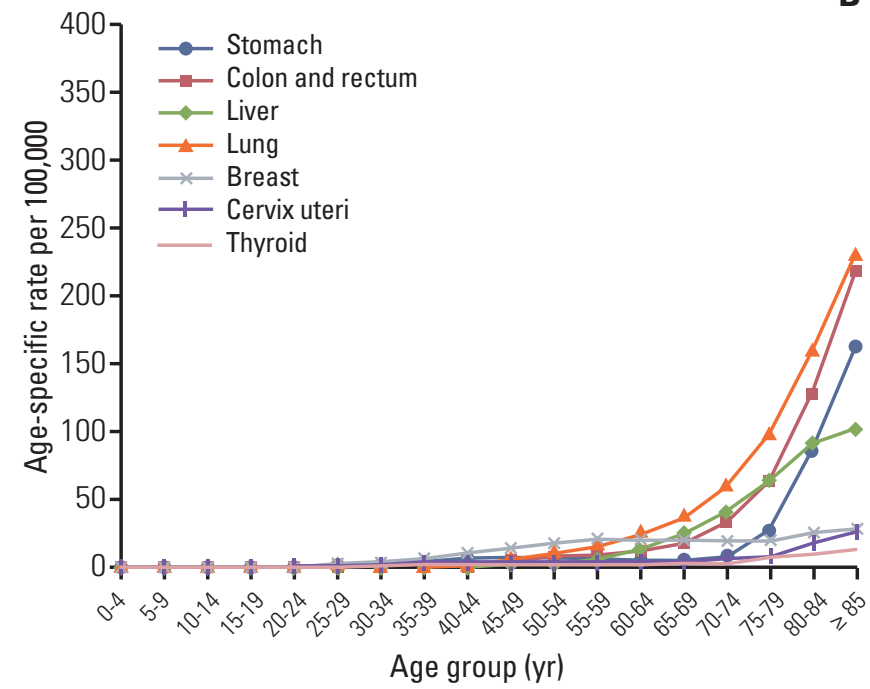

Fig. 3. Projected age-specific mortality rates of major cancers during 2019 in Korea. (A) Male. (B) Female. 
jected to be 193.9 and 123.8 , respectively, whereas the projected ASRs per 100,000 of all sites combined are expected to be 102.7 and 49.4, respectively (Table 4). The predicted five leading cancer sites causing mortality in men are predicted to be lung (CR, 54.9; ASR, 28.0), liver (CR, 30.1; ASR, 16.3), colon and rectum (CR, 18.5; ASR, 9.8), stomach (CR, 16.8 ASR, 8.9), and pancreas (CR, 13.0; ASR, 7.0). During the same period, lung cancer (CR, 20.3; ASR, 7.5) is projected to be the leading cancer cause of death in women, followed by the colon and rectum (CR, 14.9; ASR, 5.2), pancreas (CR, 12.5; ASR, 4.7), liver (CR, 11.2; ASR, 4.2), and breast (CR, 10.5; ASR, 5.7).

The predicted age-specific mortality rates of the selected cancers for males and females in 2019 are shown in further detail in Fig. 3. When examined by age, Korean men and women aged 60 years and above are expected to have the highest mortality rates from lung cancer.

\section{Conclusion}

A total of 221,347 new cancer cases and 82,344 cancer deaths are expected to occur in Korea during 2019. Lung cancer is predicted to the most common cancer among males, followed by stomach, colorectal, prostate, and liver cancers. Lung, liver, colorectal, stomach, and pancreatic cancers are expected to be the most common causes of cancer deaths among men. In women, the five leading primary sites are expected to be the breast, colorectal, stomach, thyroid, and lung cancers, while lung, colorectal, pancreatic, liver, and breast cancers are projected to be the most common causes of cancer-related deaths.

Cancer is currently one of the foremost public health concerns in Korea. Although cancer rates are anticipated to decrease somewhat, but burden of most of cancers will continue to grow with the increasing age of the population. The current projections of cancer incidence and mortality for 2019 represent an important resource for planning and evaluating cancer-control programs. As the estimates in this study are model-based, these results should be interpreted with caution. Specifically, the incidence of some cancers, such as stomach, colorectum, and thyroid cancers, started to decrease from early 2010s; thus, recent trends of these cancers contained only 5 or 6 data points for analysis, and therefore, their estimates could be unstable.

\section{Conflicts of Interest}

Conflict of interest relevant to this article was not reported.

\section{Acknowledgments}

The authors would like to specially thank the tumor registrars (Health information manager) of the KCCR-affiliated hospitals and non-KCCR-affiliated hospitals for data collecting, abstracting, and coding. Additionally, we acknowledge the cooperation of the National Health Insurance Service and Statistics Korea for the data support.

This work was supported by the National Cancer Center research grant (No. 1910130).

\section{References}

1. Statistics Korea [Internet]. Daejeon: Statistics Korea; 2019 [cited 2019 Feb 8]. Available from: http:// kosis.kr.

2. Jung KW, Won YJ, Kong HJ, Lee ES, Community of Population-Based Regional Cancer Registries. Cancer statistics in Korea: incidence, mortality, survival, and prevalence in 2015. Cancer Res Treat. 2018;50:303-16.

3. Shin HR, Won YJ, Jung KW, Kong HJ, Yim SH, Lee JK, et al. Nationwide cancer incidence in Korea, 1999 2001; first result using the national cancer incidence database. Cancer Res Treat. 2005;37:325-31.

4. Fritz A, Percy C, Jack A, Shanmugaratnam K, Sobin L, Parkin $\mathrm{DM}$, et al. International classification of diseases for oncology. 3rd ed. 1st rev. ed. Geneva: World Health Organization; 2013.

5. World Health Organization. International statistical classifica- tion of diseases and related health problems. 10th rev. ed. Geneva: World Health Organization; 1994.

6. Boyle P, Parkin DM. Statistical methods for registries. In: Jensen OM, Parkin DM, MacLennan R, Muir CS, Skeet RG, editors. Cancer registration: principles and methods. IARC Scientific Publication No. 95. Lyon International Agency for Research on Cancer; 1991. p. 126-58.

7. National Cancer Institute. Joinpoint regression program, version 4.3.1 [Internet]. Bethesda, MD: National Cancer Institute; 2016 [cited 2019 Feb 8]. Available from: http://surveillance. cancer.gov/joinpoint/.

8. Segi M. Cancer mortality for selected sites in 24 countries (1950-1957). Sendai: Tohoku University School of Medicine; 1960. 